\title{
Ozenoxacin, a New Effective and Safe Topical Treatment for Impetigo in Children and Adolescents
}

\author{
Antonio Torrelo $^{\mathrm{a}}$ Ramon Grimalt ${ }^{\mathrm{b}}$ Xavier Masramon ${ }^{\mathrm{c}}$ Núria Albareda López ${ }^{\mathrm{d}}$ \\ llonka Zsolt ${ }^{\mathrm{e}}$

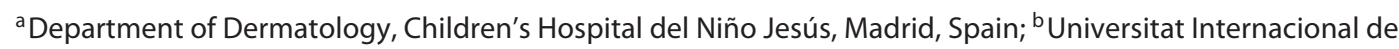 \\ Catalunya, Barcelona, Spain; 'SAIL (Servicio de Asesoría a la Investigación y Logística) SL, Barcelona, Spain;

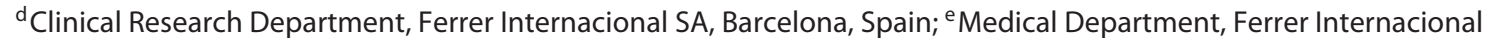 \\ SA, Barcelona, Spain
}

\section{Keywords}

Ozenoxacin · Impetigo, paediatric · Efficacy · Safety ·

Topical antibiotics

\begin{abstract}
Background: Ozenoxacin is a topical antibiotic approved in Europe to treat non-bullous impetigo in adults and children aged $\geq 6$ months. This analysis evaluated the efficacy and safety of ozenoxacin in paediatric patients by age group. Methods: Pooled data for patients aged 6 months to $<18$ years who had participated in a phase I or in two phase III clinical trials of ozenoxacin $1 \%$ cream were analysed by age group: $0.5-<2,2-<6,6-<12$, and $12-<18$ years. Results: The combined population comprised 529 patients with non-bullous impetigo treated with ozenoxacin $(n=239)$, vehicle $(n=201)$, or retapamulin as internal validation control $(n=$ 89). Studies were well matched for extent and severity of impetigo and therapeutic schedule (twice daily application for 5 days). The clinical success rate after 5 days' treatment (day $6-7$, end of therapy), and microbiological success rates after 3-4 days' treatment and at the end of therapy, were significantly higher with ozenoxacin than vehicle $(p<0.0001$ for all
\end{abstract}

comparisons). Clinical and bacterial eradication rates were higher with ozenoxacin than vehicle in each age group. No safety concerns were identified with ozenoxacin. One (0.3\%) of 327 plasma samples exceeded the lower limit of quantification for ozenoxacin, but the low concentration indicated negligible systemic absorption. Conclusion: This combined analysis supports the efficacy and safety of ozenoxacin administered twice daily for 5 days. Ozenoxacin $1 \%$ cream is a new option to consider for treatment of non-bullous impetigo in children aged 6 months to $<18$ years.

\footnotetext{
(C) 2020 The Author(s)

Published by S. Karger AG, Basel
}

\section{Introduction}

Impetigo is a bacterial skin infection common in children, with an estimated global prevalence approximately 2.5 -fold higher than that in adults [1]. The main types of impetigo are non-bullous (70\% of cases) and bullous (30\% of cases). Non-bullous impetigo, or impetigo contagiosa, is caused by Staphylococcus aureus or Streptococcus pyogenes. It is characterised by superficial honey-coloured crusted lesions on the face and extremities which

\begin{tabular}{ll}
\hline karger@karger.com & (c) 2020 The Author(s) \\
Published by S. Karger AG, Basel & Karger \\
www.karger.com/drm & This article is licensed under the Creative Commons Attribution- \\
Narger & NonCommercial-NoDerivatives 4.0 International License (CC BY- \\
NC-ND) (http://www.karger.com/Services/OpenAccessLicense). \\
Usage and distribution for commercial purposes as well as any dis- \\
tribution of modified material requires written permission.
\end{tabular}

Ilonka Zsolt

Ferrer Internacional SA

Avda. Diagonal 549; 5a planta

ES-08029 Barcelona (Spain)

E-Mail izsolt@ferrer.com 


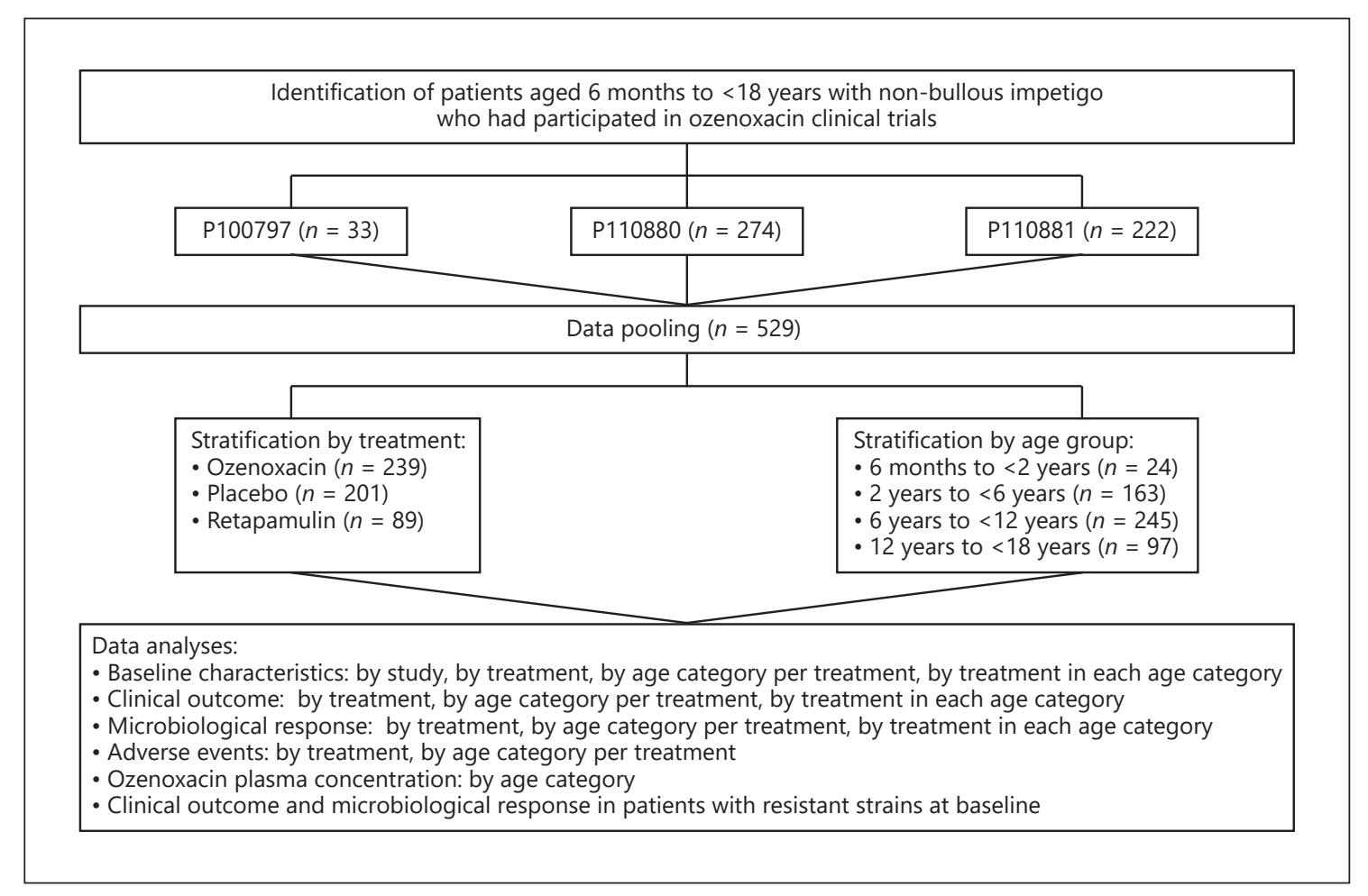

Fig. 1. Flowchart of Methods: overview of study procedures.

can spread to surrounding areas by auto-inoculation and transmit to close contacts [2-6]. Bullous impetigo is caused by toxin-producing $S$. aureus and is characterised by rapidly enlarging, flaccid bullae that can rupture and ooze, leaving a pathognomonic collarette of scales. Bullous impetigo tends to affect the trunk, extremities, and moist intertriginous areas such as the axillae, neck fold, and diaper area. Extensive lesions may be accompanied by systemic symptoms such as fever, diarrhoea, and weakness [2-6].

Factors associated with an increased risk of impetigo include residing in a tropical climate, crowded living conditions, poor hygiene, socio-economic deprivation, host immunity status and playing close-contact sports $[1,2,5$, 6]. As impetigo is highly contagious, it is a particular concern for schools and day care centres where the likelihood of transmission is increased [7]. Clinical practice guidelines recommend the use of topical antibacterial agents for small localised areas of lesions and recommend oral antibiotics for the treatment of numerous or more extensive lesions that are not responding to topical therapy, and for systemic infection [8].

Ozenoxacin is a novel non-fluorinated quinolone. As of May 2019, ozenoxacin 1\% cream has been approved in
12 countries of the European Union (EU) for topical treatment of non-bullous impetigo in patients aged 6 months and older [9]. Although relatively few patients under 6 months of age and/or with bullous impetigo were enrolled in pivotal phase III clinical trials of ozenoxacin $[10,11]$, in the USA and Canada ozenoxacin $1 \%$ cream is indicated for topical treatment of non-bullous and bullous impetigo in patients aged 2 months and older [12, 13].

Comparative in vitro studies have shown that ozenoxacin has potent antimicrobial activity against staphylococci and streptococci, the major pathogens involved in impetigo. Ozenoxacin also has a broad range of activity against methicillin-, mupirocin-, and ciprofloxacin-resistant strains of $S$. aureus $[14,15]$. Ozenoxacin's dual inhibitory activity against the bacterial replication enzymes, DNA gyrase and topoisomerase IV, protects it from development of resistance [16], and the absence of a fluorine atom in its molecular structure confers a better safety profile than that of fluorinated quinolones, including a lack of quinolone-induced chondrotoxicity [17]. Topical ozenoxacin is negligibly absorbed [18], and phase I studies showed excellent dermal tolerability [19]. Collectively, these properties suggest that ozenoxacin may be a valuable option for empirical therapy of localised impetigo. 
Table 1. Demographic and baseline characteristics of the combined safety and efficacy population according to treatment

\begin{tabular}{|c|c|c|c|c|}
\hline \multicolumn{5}{|l|}{ Study, $n(\%)$} \\
\hline Phase I [20] & $33(6.2)$ & $33(13.8)$ & $0(0.0)$ & $0(0.0)$ \\
\hline Phase III [10] & $274(51.8)$ & $94(39.3)$ & $91(45.3)$ & $89(100.0)$ \\
\hline Phase III [11] & $222(42.0)$ & $112(46.9)$ & $110(54.7)$ & $0(0.0)$ \\
\hline$\geq 2$ to $<6$ years & $163(30.8)$ & $83(34.7)$ & $49(24.4)$ & $31(34.8)$ \\
\hline$\geq 6$ to $<12$ years & $245(46.3)$ & $94(39.3)$ & $106(52.7)$ & $45(50.6)$ \\
\hline$\geq 12$ to $<18$ years & $97(18.3)$ & $45(18.8)$ & $39(19.4)$ & $13(14.6)$ \\
\hline \multicolumn{5}{|l|}{ Gender, $n(\%)$} \\
\hline Female & $226(42.7)$ & $107(44.8)$ & $87(43.3)$ & $32(36.0)$ \\
\hline Male & $303(57.3)$ & $132(55.2)$ & $114(56.7)$ & $57(64.0)$ \\
\hline \multicolumn{5}{|l|}{ Race, $n(\%)$} \\
\hline Asian & $20(3.8)$ & $10(4.2)$ & $10(5.0)$ & $0(0.0)$ \\
\hline Affected areas (mean $\pm \mathrm{SD}), n$ & $3.1 \pm 3.2$ & $3.1 \pm 2.6$ & $2.8 \pm 2.8$ & $3.8 \pm 4.9$ \\
\hline Total affected area (mean $\pm \mathrm{SD}), \mathrm{cm}^{2}$ & $7.2 \pm 10.8$ & $7.3 \pm 10.2$ & $7.8 \pm 11.3$ & $5.7 \pm 11.3$ \\
\hline \multicolumn{5}{|l|}{ Baseline Skin Infection Rating Scale total score } \\
\hline$($ mean $\pm \mathrm{SD})$ & $11.2 \pm 4.5$ & $10.9 \pm 4.6$ & $10.7 \pm 4.7$ & $13.3 \pm 3.4$ \\
\hline \multicolumn{5}{|l|}{ Microbiological susceptibility, $n(\%)$} \\
\hline Total & 236 & 89 & 78 & 69 \\
\hline Resistant & $10(4.2)$ & $5(5.6)$ & $3(3.8)$ & $2(2.9)$ \\
\hline Susceptible & $226(95.8)$ & $84(94.4)$ & $75(96.2)$ & $67(97.1)$ \\
\hline
\end{tabular}

Clinical studies of ozenoxacin $1 \%$ cream (twice daily for 5 days) demonstrated that it is effective and well tolerated in children and adults with impetigo $[10,11,20]$. To further ascertain the profile of ozenoxacin specifically in the paediatric population, we extracted and analysed data for children and adolescents aged 6 months to $<18$ years who had participated in ozenoxacin clinical trials.

\section{Methods}

For further details, see the supplementary material (for all online suppl. material, see www.karger.com/doi/10.1159/000504536) (Fig. 1) [9-11, 20].

\section{Results}

\section{Demographics and Baseline Clinical Characteristics}

The pooled efficacy and safety population consisted of 529 patients aged $\geq 6$ months to $<18$ years with non-bullous impetigo who were enrolled in phase I [20] or phase
III $[10,11]$ clinical trials of ozenoxacin. Most patients were recruited in South Africa $(n=313)$, the USA $(n=$ 79 ), or Germany $(n=60)$.

Demographic and baseline characteristics of the pooled efficacy and safety population are summarised in Table 1 according to treatment with ozenoxacin $(n=$ $239)$, vehicle $(n=201)$, or retapamulin $(n=89)$. Demographic parameters and clinical characteristics were similar among treatment groups. Most patients were aged $6-<12$ years $(n=245 ; 46.3 \%)$ or $2-<6$ years $(n=163$; $30.8 \%)$. There was a slight male preponderance $(57.3 \%)$, and the most common ethnic groups were Black (47.4\%) and Caucasian/White (36.9\%). At baseline, patients had a mean Skin Infection Rating Scale total score of $11.2 \pm$ 4.5 , a mean of $3.1 \pm 3.2$ affected areas, and a mean total affected area of $7.2 \pm 10.8 \mathrm{~cm}^{2}$. Most patients $(95.8 \%)$ had microbiological susceptibility at baseline.

Demographic and baseline characteristics of the pooled efficacy and safety population treated with ozenoxacin or vehicle and stratified by age group are shown in Table 2. The mean Skin Infection Rating Scale total score at baseline ranged from $10.0 \pm 4.1$ in the 6 - to $<12$ - 
Table 2. Demographic and baseline characteristics of the combined safety and efficacy population according to treatment and age group

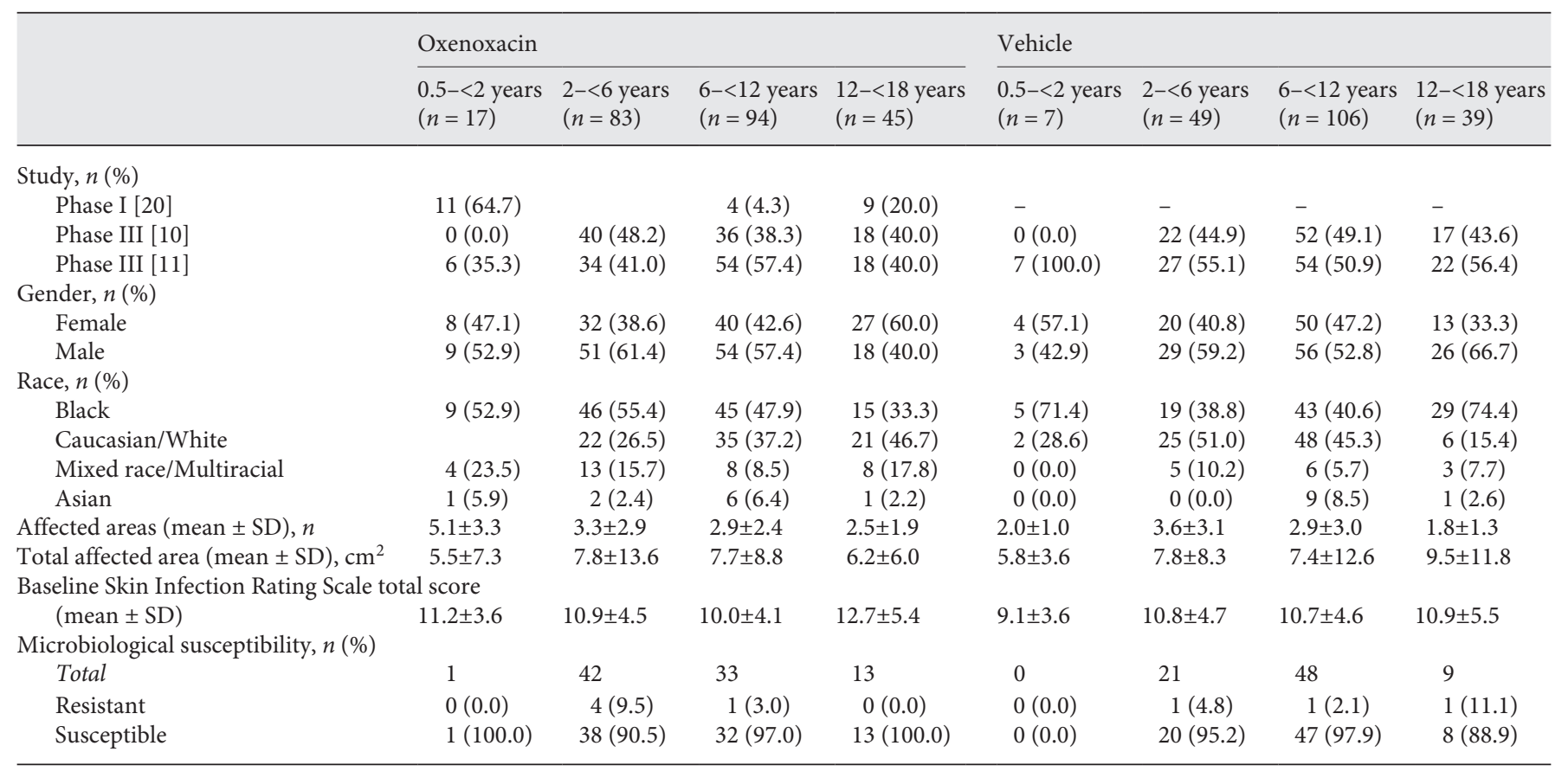

year age group to $12.7 \pm 5.4$ in the 12 - to $<18$-year age group in patients treated with ozenoxacin, and from 9.1 \pm 3.6 in the 0.5 - to $<2$-year age group to $10.9 \pm 5.5$ in the 12 - to $<18$-year age group in patients treated with vehicle. The mean number of affected areas at baseline ranged from $2.5 \pm 1.9$ in the 12 - to $<18$-year age group to $5.1 \pm$ 3.3 in the 0.5 - to $<2$-year age group in patients treated with ozenoxacin, and from $1.8 \pm 1.3$ in the 12 - to $<18$-year age group to $3.6 \pm 3.1$ in the 2 - to $<6$-year age group in patients treated with vehicle. The mean total affected area at baseline ranged from $5.5 \pm 7.3 \mathrm{~cm}^{2}$ in the 0.5 - to $<2$-year age group to $7.8 \pm 13.6 \mathrm{~cm}^{2}$ in the 2 - to $<6$-year age group in patients treated with ozenoxacin, and from $5.8 \pm 3.6 \mathrm{~cm}^{2}$ in the 0.5 - to $<2$-year age group to $9.5 \pm 11.8$ $\mathrm{cm}^{2}$ in the 12 - to $<18$-year age group in patients treated with vehicle.

\section{Clinical Outcomes}

The clinical success rate in the pooled paediatric population after 5 days' treatment was significantly higher with ozenoxacin than vehicle $(p<0.0001)$ (Fig. 2). In each of the four age groups ozenoxacin was associated with a higher clinical success rate compared with vehicle. Respective clinical success rates by age group for ozenoxacin versus vehicle were: 100 versus $57.1 \%$ for $0.5-<2$ years; 88.0 versus $71.4 \%$ for $2-<6$ years; 91.5 versus $77.4 \%$ for $6-<12$ years; and 93.3 versus $79.5 \%$ for $12-<18$ years. Re- sults in the retapamulin control arm by age group were $93.5 \%$ for $2-<6$ years, $71.1 \%$ for $6-<12$ years, and $76.9 \%$ for $12-<18$ years, respectively.

\section{Microbiological Response}

Microbiological response following ozenoxacin or vehicle treatment was evaluated at visit 2 (day 3-4 of treatment) and visit 3 (day 6-7, end of 5 days' therapy). In the pooled population, ozenoxacin was associated with significantly higher microbiological success rates than vehicle at visit 2 (Fig. 3) and visit 3 (Fig. 4) $(p<0.0001$ at both time points). In each age group, ozenoxacin was associated with a higher microbiological success rate at both visits compared with vehicle. At visit 2 , the respective microbiological success rates for ozenoxacin and vehicle were: 100 versus $60 \%$ for $0.5-<2$ years; 81.8 versus $55.3 \%$ for $2-$ $<6$ years; 87.7 versus $59.8 \%$ for $6-<12$ years; and 81.8 versus $42.3 \%$ for $12-<18$ years (Fig. 3 ). At visit 3 , the respective microbiological success rates for ozenoxacin and vehicle were: 100 versus $60 \%$ for $0.5-<2$ years; 92.2 versus $70.3 \%$ for $2-<6$ years; 97.2 versus $73.8 \%$ for $6-<12$ years; and 90.5 versus $64.0 \%$ for $12-<18$ years (Fig. 4 ).

Microbiological success rates in the retapamulin control arm by age group were $60 \%$ for $2-<6$ years, $50 \%$ for $6-<12$ years, and $46.2 \%$ for $12-<18$ years, respectively, at visit 2 , and $87.1 \%$ for $2-<6$ years, $82.2 \%$ for $6-<12$ years, and $84.6 \%$ for $12-<18$ years, respectively, at visit 3 . 
Fig. 2. Clinical success rates after 5 days' treatment (day 6-7; end of therapy) in ozenoxacin- and vehicle-treated paediatric patients stratified by age group. Clinical success was defined as cure or improvement according to predefined criteria. ${ }^{* * *} p<$ 0.0001 .

Fig. 3. Microbiological success rates at visit 2 (day 3-4 of treatment) in ozenoxacinand vehicle-treated paediatric patients stratified by age group. Microbiological success was defined as the absence of original pathogen(s) in culture of the baseline specimen with/without the presence of new micro-organisms. ${ }^{* * *} p<0.0001$.

Fig. 4. Microbiological success rates at visit 3 (day 6-7, end of 5 days' therapy) in ozenoxacin- and vehicle-treated paediatric patients stratified by age group. Microbiological success was defined as the absence of original pathogen(s) in culture of the baseline specimen with/without the presence of new micro-organisms. ${ }^{* * *} p<0.0001$.
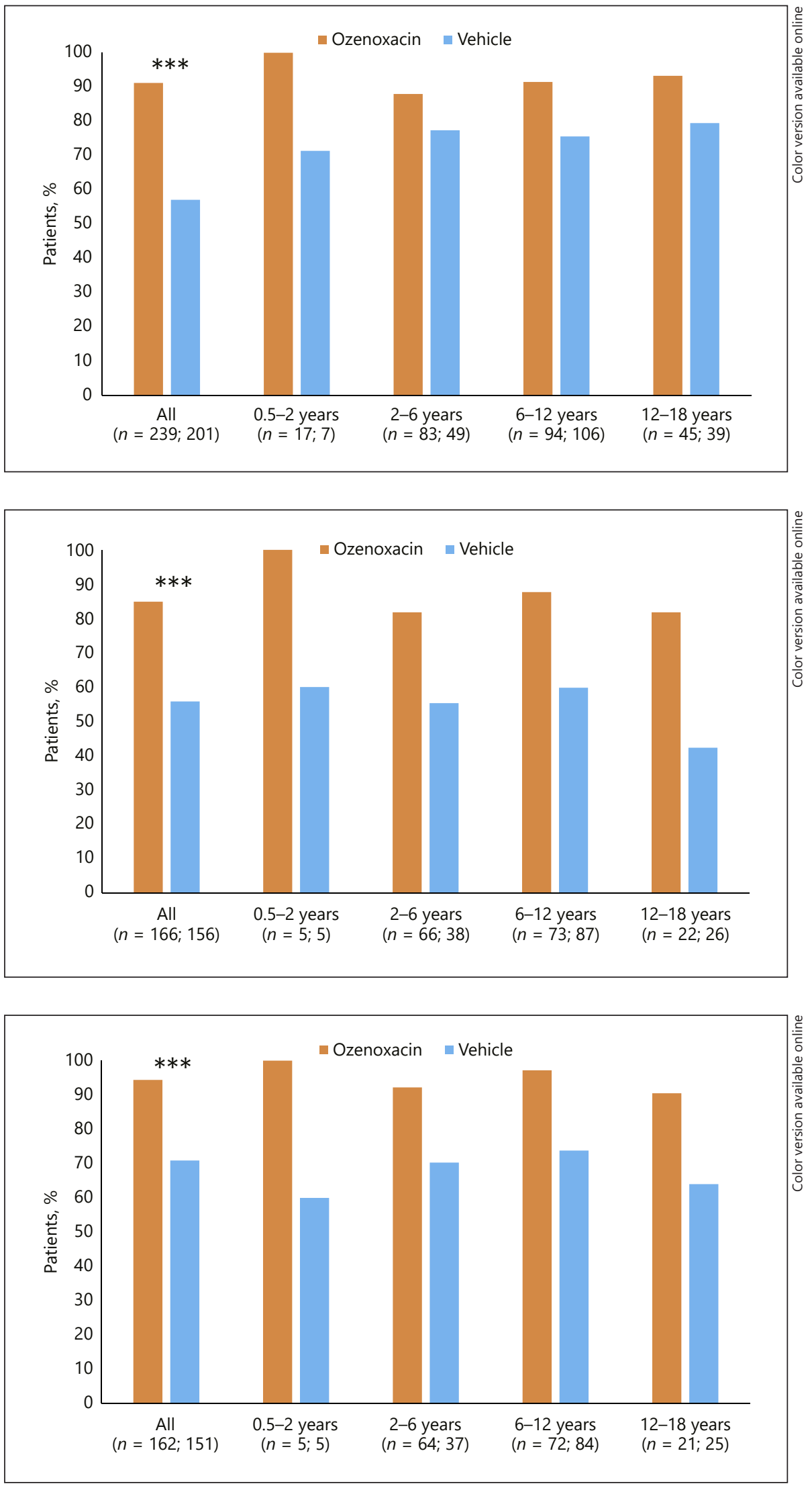
Table 3. Ozenoxacin plasma samples above the lower limit of quantification

\begin{tabular}{lccccc}
\hline & \multicolumn{2}{l}{ Patient groups } \\
\cline { 2 - 6 } & $\begin{array}{l}\text { All } \\
(n=33)\end{array}$ & $\begin{array}{l}0.5-<2 \text { years } \\
(n=11)\end{array}$ & $\begin{array}{l}2-<6 \text { years } \\
(n=9)\end{array}$ & $\begin{array}{l}\text { 6-<12 years } \\
(n=4)\end{array}$ & $\begin{array}{l}12-<18 \text { years } \\
(n=9)\end{array}$ \\
\hline Samples, $n$ & 327 & 74 & 64 & 36 & 153 \\
Samples above the LLQ, $n(\%)^{1}$ & $1(0.3)$ & $0(0.0)$ & $1(1.6)$ & $0(0.0)$ & $0(0.0)$ \\
\hline
\end{tabular}

Data from Gropper et al. [20]. LLQ, lower limit of quantification: $0.489 \mathrm{ng} / \mathrm{mL} .{ }^{1}$ As a proportion of the number of samples.

Outcomes in Patients with Resistant Strains

At baseline, 10 patients had resistant bacterial strains, including 2 patients allocated to retapamulin. The clinical success rate (cure or improvement) after 5 days' treatment was $100 \%$ for 5 patients treated with ozenoxacin and $100 \%$ for 3 patients treated with vehicle. Ozenoxacin was superior to vehicle in terms of microbiological response. All 5 patients (100\%) treated with ozenoxacin achieved microbiological eradication by visit 2 (day $3-4$ of treatment) which was maintained at visit 3 (day 6-7, end of 5 days' therapy). One (33.3\%) of 3 patients treated with vehicle achieved microbiological success at visit 2 and visit 3 .

\section{Safety}

Across studies, there were 34 mild $(n=25)$ or moderate $(n=9)$ adverse events (AEs) reported in $28(5.3 \%)$ patients during the course of treatment. No serious AEs were reported. A total of 15 AEs (12 mild, 3 moderate) were reported in 13 patients (5.4\%) treated with ozenoxacin; 6 AEs ( 3 mild, 3 moderate) were reported in 6 patients (3.0\%) treated with vehicle, and 13 AEs ( 9 mild, 4 moderate) were reported in 9 patients $(10.1 \%)$ treated with retapamulin. No AE reported for ozenoxacin or vehicle was considered to be drug related. One AE reported with retapamulin, which occurred in the 6 - to $<12$-year age group, was considered to be drug related.

Pharmacokinetic parameters were available for 33 paediatric patients treated with ozenoxacin in the phase I study (Table 3). A plasma concentration above the lower limit of quantification for ozenoxacin $(0.489 \mathrm{ng} / \mathrm{mL})$ was identified in a sample from a patient in the 2 - to $<6$-year age group, representing $0.3 \%$ of 327 plasma samples tested. The measured concentration of $0.614 \mathrm{ng} / \mathrm{mL}$ indicated negligible systemic absorption.

\section{Discussion}

The efficacy and safety of ozenoxacin in the paediatric population with non-bullous impetigo were examined by pooling data for patients aged 6 months to $<18$ years of age who had participated in phase I [20] or phase III [10, 11] clinical trials. In the combined population, clinical and microbiological success rates with ozenoxacin were significantly superior to those with vehicle, confirming the results of the pivotal phase III trials. In analyses by age group, ozenoxacin demonstrated earlier and superior bacterial eradication compared with vehicle in all age groups. Clinical success rates after 5 days' treatment ranged from 88.0 to $100 \%$ with ozenoxacin, and from 57.1 to $79.5 \%$ with vehicle. Microbiological success rates with ozenoxacin ranged from 81.8 to $100 \%$ after 3-4 days of treatment, and from 90.5 to $100 \%$ after 5 days' treatment. Corresponding microbiological success rates were considerably lower with vehicle $(42.3-60 \%$ and $60-73.8 \%$ at visit 2 and visit 3, respectively) and also in the retapamulin control arm (46.2-60\% and $82.2-87.1 \%$ at visit 2 and visit 3 , respectively). Due to the rapid bactericidal activity of ozenoxacin as indicated in this subanalysis, its early microbiological eradication activity may have critical importance in restricting the transmission of impetigo, a highly contagious condition.

There were no safety concerns among 239 paediatric patients treated with ozenoxacin across studies regardless of age; none of the 15 AEs reported with ozenoxacin was considered to be treatment related. The excellent dermal tolerability to topical ozenoxacin observed during clinical use aligns with phase I studies showing little to no tendency for single or repeated doses of ozenoxacin to cause irritation, sensitization, phototoxicity, or photoallergy [19]. Likewise, the virtual lack of systemic absorption after administration of topical ozenoxacin twice daily for 5 days is consistent with phase I studies showing no sys- 
temic absorption after increasing single or multiple doses of ozenoxacin applied to intact or abraded skin [18].

National primary care treatment guidelines in European countries recommend fusidic acid, mupirocin, or retapamulin as topical treatments for impetigo [21]. However, the development and spread of staphylococcal strains resistant to these agents is a concern. Resistance to fusidic acid has been reported in Europe [22-26]. Fusidic acid resistance in strains of $S$. aureus causing impetigo is due to clonal expansion of the epidemic European fusidic acid-resistant impetigo clone (EEFIC) [23, 24, 27, 28], although EEFIC-related outbreaks have declined markedly since their peak in the early 2000s [29,30]. Resistance to mupirocin has also been reported in Europe [31-33] and may be increasing. Investigators in Greece reported an increase from $4.2 \%$ in 2013 to $37.7 \%$ in 2016 in the rate of mupirocin-resistant $S$. aureus strains among community-associated staphylococcal infections, concurrent with increasing rates of resistance to fusidic acid [34].

Efforts to promote judicious use of antibiotics have centred mainly on oral and intravenous formulations; however, the consequences of drug resistance also extend to topical antibiotics [35]. Appropriate use of topical antibacterials in evidence-based indications provides important benefits. Delivering a high concentration of drug directly to infected areas of skin can overcome bacterial resistance, and minimal dermal absorption avoids potential systemic side effects associated with oral therapy [16].

Antibiotics with a rapid bactericidal effect are important for symptom resolution in a highly contagious disease such as impetigo. In susceptibility studies, ozenoxacin was shown to be bactericidal against methicillin-susceptible and methicillin-resistant $S$. aureus, methicillinsusceptible and methicillin-resistant $S$. epidermidis - including levofloxacin-susceptible and levofloxacin-resistant isolates - and against $S$. pyogenes and $S$. agalactiae [15]. Although the number of patients with resistant strains in the current analysis was limited, all 5 patients treated with ozenoxacin achieved bacterial eradication within 3 days of commencing treatment.

The main purpose of undertaking this analysis was to ascertain the efficacy and safety of topical ozenoxacin in the primary target population in the EU, namely paediatric patients aged 6 months or older with non-bullous impetigo. Study homogeneity with regard to inclusion/exclusion criteria and therapeutic schedule facilitated data pooling in order to evaluate outcomes in a larger patient population. The main limitation of the analysis is the few patients in the 0.5 - to $<2$-year age category (ozenoxacin $n=17$; vehicle $n=7$ ), although this is consistent with the disease pattern, as non-bullous impetigo has a peak incidence in children aged 2-6 years [2]. Similar clinical and microbiological success rates and excellent tolerability to ozenoxacin observed across age groups support its EU indication to treat impetigo in children aged 6 months and older.

\section{Conclusions}

Although fusidic acid and mupirocin continue to be widely used in Europe to treat impetigo, resistance to these antibacterial agents is observed and may be increasing. Ozenoxacin, which has potent antibacterial activity against staphylococci and streptococci, a rapid bactericidal effect and low potential to select resistant mutants, appears to be a useful alternative to treat non-bullous impetigo in children and adolescents aged 6 months to 17 years.

\section{Key Message}

This pooled analysis confirmed the efficacy and safety of ozenoxacin in children with non-bullous impetigo.

\section{Acknowledgements}

Writing assistance was provided by Rob Furlong and Kerry Dechant on behalf of Content Ed Net (Madrid, Spain) with funding from Ferrer Internacional SA (Barcelona, Spain).

\section{Statement of Ethics}

All studies included in the pooled analyses were conducted in accordance with principles outlined in the Declaration of Helsinki and the International Conference on Harmonisation Good Clinical Practice guidelines.

\section{Disclosure Statement}

X.M. is an employee of SAIL. N.A.L. and I.Z. are employees of Ferrer Internacional. The remaining authors have no conflicts of interest to declare.

\section{Funding}

The analysis was funded by Ferrer Internacional SA, Barcelona, Spain.
Ozenoxacin for Topical Treatment of

Impetigo in Children and Adolescents
Dermatology 2020;236:199-207

DOI: $10.1159 / 000504536$ 


\section{Author Contributions}

All authors contributed to the development of the trial protocol and were involved in drafting the manuscript or revising it critically for important intellectual content. N.A.L. and I.Z. partici- pated in the conception and design of the study. Analysis and interpretation of the data were supported by A.T. and X.M. R.G. conducted a critical review of the manuscript, contributing important intellectual content. All authors gave final approval of the version for publication.

\section{References}

1 Bowen AC, Mahé A, Hay RJ, Andrews RM, Steer AC, Tong SY, et al. The global epidemiology of impetigo: a systematic review of the population prevalence of impetigo and pyoderma. PLoS One. 2015 Aug;10(8):e0136789.

2 Sladden MJ, Johnston GA. Common skin infections in children. BMJ. 2004;329:95-9. https://doi.org/10.1136/bmj.329.7457.95.

3 Sladden MJ, Johnston GA. Current options for the treatment of impetigo in children. Expert Opin Pharmacother. 2005;6:2245-56. https://doi.org/10.1517/14656566.6.13.2245.

4 Cole C, Gazewood J. Diagnosis and treatment of impetigo. Am Fam Physician. 2007 Mar; 75(6):859-64.

5 Hartman-Adams H, Banvard C, Juckett G. Impetigo: diagnosis and treatment. Am Fam Physician. 2014;90:229-35

6 Lewis LS. Impetigo. Medscape. Available from https://emedicine.medscape.com/article/965254-overview [cited 2019 March 26].

7 Kimberlin DW, Brady MT, Jackson MA, Long SS, editors. Red Book. 2015 Report of the Committee on Infectious Diseases. 30th ed. Elk Grove Village, IL, USA: American Academy of Pediatrics; 2015.

8 Stevens DL, Bisno AL, Chambers HF, Dellinger EP, Goldstein EJ, Gorbach SL, Hirschmann JV, Kaplan SL, Montoya JG, Wade JC. Practice guidelines for the diagnosis and management of skin and soft tissue infections: 2014 update by the Infectious Diseases Society of America. Clin Infect Dis. 2014;59: 147-59.

9 Medicine \& Healthcare Products Regulatory Agency. Ozadub (ozenoxacin) $10 \mathrm{mg} / \mathrm{g}$ cream. Summary of product characteristics. Ferrer Internacional; 2018. Available from http://www.mhra.gov.uk/home/groups/spcpil/documents/spcpil/con1541740763173. pdf [cited 2019 April 5].

10 Gropper S, Albareda N, Chelius K, Kruger D, Mitha I, Vahed Y, Gani M, García-Alonso F; Ozenoxacin in Impetigo Trial Investigators Group. Ozenoxacin 1\% cream in the treatment of impetigo: a multicenter, randomized, placebo- and retapamulin-controlled clinical trial. Future Microbiol. 2014;9:1013-23.

11 Rosen T, Albareda N, Rosenberg N, Alonso FG, Roth S, Zsolt I, Hebert AA. Efficacy and safety of ozenoxacin cream for treatment of adult and paediatric patients with impetigo: a randomized clinical trial. JAMA Dermatol. 2018;154:806-13.
12 US Food \& Drug Administration. Xepi ${ }^{\mathrm{TM}}$ (ozenoxacin) $1 \%$ cream, for topical use. Prescribing information. Medimetriks Pharmaceuticals Inc; 2017. Available from https:// www.accessdata.fda.gov/drugsatfda_docs/ label/2017/208945lbl.pdf [cited 2019 April 5]. 13 Health Canada. Ozanex (ozenoxacin) 1\% cream. Product monograph. Ferrer Internacional; 2016. Available from https://pdf.hres. ca/dpd_pm/00039119.pdf [cited 2019 April 5].

14 López Y, Tato M, Espinal P, Garcia-Alonso F, Gargallo-Viola D, Cantón R, et al. In vitro activity of ozenoxacin against quinolone-susceptible and quinolone-resistant gram-positive bacteria. Antimicrob Agents Chemother. 2013 Dec;57(12):6389-92.

15 Canton R, Morrissey I, Vila J, Tato M, GarcíaCastillo M, López Y, Gargallo-Viola D, Zsolt I. Comparative in vitro antibacterial activity of ozenoxacin against Gram-positive clinical isolates. Future Microbiol. 2018;13:3-19. https://doi.org/10.2217/fmb-2017-0289.

16 Vila J, Hebert AA, Torrelo A, López Y, Tato M, García-Castillo M, et al. Ozenoxacin: a review of preclinical and clinical efficacy. Expert Rev Anti Infect Ther. 2019 Mar;17(3):159-68.

17 González Borroto JI, Awori MS, Chouinard L, Smith SY, Tarragó C, Blazquez T, et al. Studies on articular and general toxicity of orally administered ozenoxacin in juvenile rats and dogs. Future Microbiol. 2018 May;13(6 Suppl):31-40.

18 Gropper S, Albareda N, Santos B, Febbraro S. Systemic bioavailability, safety and tolerability of topical ozenoxacin in healthy adult volunteers. Future Microbiol.2014;9(8 Suppl):S11-6. https://doi.org/10.2217/fmb.14.82.

19 Gropper S, Cepero AL, Dosik JS, LaStella P, Siemetzki H, Wigger-Alberti W. Cumulative irritation, sensitizing potential, phototoxicity and photoallergy of ozenoxacin in healthy adult volunteers. Future Microbiol. 2014;9:S23-S31. https://doi.org/10.2217/fmb.14.84.

20 Gropper S, Cepero AL, Santos B, Febbraro S. Systemic bioavailability and safety of twicedaily topical ozenoxacin $1 \%$ cream in adults and children with impetigo. Future Microbiol. 2014;9:S33-S40.

21 van Bijnen EM, Paget WJ, den Heijer CD, Stobberingh EE, Bruggeman CA, Schellevis FG; APRES Study Team. Primary care treatment guidelines for skin infections in Europe: congruence with antimicrobial resistance found in commensal Staphylococcus aureus in the community. BMC Fam Pract. 2014 Oct;15(1): 175 .
22 Howden BP, Grayson ML. Dumb and dumber-the potential waste of a useful antistaphylococcal agent: emerging fusidic acid resistance in Staphylococcus aureus. Clin Infect Dis. 2006 Feb;42(3):394-400.

23 O’Neill AJ, Larsen AR, Skov R, Henriksen AS, Chopra I. Characterization of the epidemic European fusidic acid-resistant impetigo clone of Staphylococcus aureus. J Clin Microbiol. 2007 May;45(5):1505-10.

24 Denton M, O'Connell B, Bernard P, Jarlier V, Williams Z, Henriksen AS. The EPISA study: antimicrobial susceptibility of Staphylococcus aureus causing primary or secondary skin and soft tissue infections in the community in France, the UK and Ireland. J Antimicrob Chemother. 2008 Mar;61(3):586-8.

25 Alsterholm M, Flytström I, Bergbrant IM, Faergemann J. Fusidic acid-resistant Staphylococcus aureus in impetigo contagiosa and secondarily infected atopic dermatitis. Acta Derm Venereol. 2010;90(1):52-7.

26 Castanheira M, Watters AA, Mendes RE, Farrell DJ, Jones RN. Occurrence and molecular characterization of fusidic acid resistance mechanisms among Staphylococcus spp. from European countries (2008). J Antimicrob Chemother. 2010 Jul;65(7):1353-8.

27 Laurent F, Tristan A, Croze M, Bes M, Meugnier $\mathrm{H}$, Lina $\mathrm{G}$, et al. Presence of the epidemic European fusidic acid-resistant impetigo clone (EEFIC) of Staphylococcus aureus in France. J Antimicrob Chemother. 2009 Feb; 63(2):420-1.

28 Rijnders MI, Wolffs PF, Hopstaken RM, den Heyer M, Bruggeman CA, Stobberingh EE. Spread of the epidemic European fusidic acid-resistant impetigo clone (EEFIC) in general practice patients in the south of The Netherlands. J Antimicrob Chemother. 2012 May;67(5):1176-80.

29 Rørtveit S, Skutlaberg DH, Langeland N, Rortveit G. Impetigo in a population over 8.5 years: incidence, fusidic acid resistance and molecular characteristics. J Antimicrob Chemother. 2011 Jun;66(6):1360-4.

30 Rørtveit S, Skutlaberg DH, Langeland N, Rortveit $\mathrm{G}$. The decline of the impetigo epidemic caused by the epidemic European fusidic acid-resistant impetigo clone: an 11.5year population-based incidence study from a community in Western Norway. Scand J Infect Dis. 2014 Dec;46(12):832-7. 
31 Rossney A, O'Connell S. Emerging high-level mupirocin resistance among MRSA isolates in Ireland. Euro Surveill. 2008 Apr;13(14): 8084.

32 Sareyyüpoğlu B, Ozyurt M, Haznedaroğlu T, Ardiç N. Detection of methicillin and mupirocin resistance in staphylococcal hospital isolates with a touchdown multiplex polymerase chain reaction. Folia Microbiol (Praha). 2008;53(4):363-7.
33 Desroches M, Potier J, Laurent F, Bourrel AS, Doucet-Populaire F, Decousser JW, et al.; Microbs Study Group. Prevalence of mupirocin resistance among invasive coagulase-negative staphylococci and methicillin-resistant Staphylococcus aureus (MRSA) in France: emergence of a mupirocin-resistant MRSA clone harbouring mupA. J Antimicrob Chemother. 2013 Aug;68(8):1714-7.
34 Doudoulakakis A, Spiliopoulou I, Spyridis N, Giormezis N, Kopsidas J, Militsopoulou M, Lebessi E, Tsolia M. Emergence of a Staphylococcus aureus clone resistant to mupirocin and fusidic acid carrying exotoxin genes and causing mainly skin infections. J Clin Microbiol. 2017;55:2529-37.

35 Lapolla WJ, Levender MM, Davis SA, Yentzer BA, Williford PM, Feldman SR. Topical antibiotic trends from 1993 to 2007: use of topical antibiotics for non-evidence-based indications. Dermatol Surg. 2011;37:1427-33. 